\title{
Health Care Service Quality and Availability of Skilled Health Workforce: A Panel Data Modelling of the UK, USA and Israel
}

\author{
Anand Chand ${ }^{1} \&$ Suwastika Naidu ${ }^{1}$ \\ ${ }^{1}$ School of Management \& Public Administration, The University of the South Pacific, Private Mail Bag, Suva, \\ Fiji Islands \\ Correspondence: Anand Chand, School of Management \& Public Administration, The University of the South \\ Pacific, Private Mail Bag, Suva, Fiji Islands. Tel: 679-323-2541. E-mail: chand_a@usp.ac.fj
}

Received: September 10, 2017

doi:10.5539/mas.v11n10p152
Accepted: September 22, 2017 Online Published: September 30, 2017

URL: https://doi.org/10.5539/mas.v11n10p152

\begin{abstract}
In the recent decade, as the number of new health related issues are on the rise, more qualified medical specialists are needed, who can advocate the importance of adopting innovative means of diagnosing health problems. There are many qualitative studies that has emphasised that there is two way relationships between health care service quality and availability of skilled health workforce; however, the significance of this relationship is still unclear. This study utilises the panel data modelling technique (PDMT) to examine the relationship between health care service quality and availability of skilled health workforce by drawing data from the Organisation for Economic Cooperation and Development (OECD) database. Based on the availability of data, three countries were studied in this paper and these three countries are on USA, UK and Israel. The findings from this study showed that the status quo of the health care service delivery can be improved in the USA and the UK if more nurses, irrespective of domestic or foreign trained nurses, are hired. In the context of Israel, more locally trained doctors and nurses rather than foreign trained doctors and nurses needs to be hired, as locally trained doctors are better able to communicate issues related to local public health to the patients.
\end{abstract}

Keywords: Skilled Medical Specialists, Patient Satisfaction, OECD, USA, UK, Israel

\section{Introduction}

Both qualitative and quantitative studies have increasingly acknowledged that there exists a two sided relationship between health care service quality and availability of skilled health workforce; however, the significance level of this relationship is still unclear (Bartlett 1984; Weinman 2004; Cooper et al. 2006; Smedley et al. 2003; Fung and Hays 2008; Feldman-Stewart and Brundage 2009). In the recent decade, as the number of new health related issues are on the rise, qualified medical specialists are needed, who can advocate the importance of adopting innovative means of diagnosing health problems. There are numerous advantages of having skilled and qualified nurses in the health system, and two of these advantages are discussed here. First, skilled and qualified health workforce is able to reduce each patients transition time to recovery. In many parts of the world, doctors provide standardized solutions to patient's health problems. On this note, medical specialists need to realise that there is no one universal solution to patient's health problems. Therefore, medical specialists need to adopt customised rather than standardised approach in diagnosing each patient's health related issues (Young 2013; Glinos 2015). Second, skilled and qualified health workforce is able to find effective and innovative means of diagnosing patient's health problems. For instance, the use of advanced and modern technology in neurosurgery and cardiology has resulted in the longevity of the patient's life (Golan et al. 2011; Lichtenberg 2014).

\section{Research Question}

Is there a two way relationships between health care service quality and availability of skilled health workforce in a country?

This study uses the Sociocultural Theory to examine the relationship between health care service quality and availability of skilled health workforce. The variations in the research findings can be explained by investigating it in the light of the differences in the sociocultural environment that is present in each of these countries. There are two important reasons why this study needs to be conducted. First, none of the existing studies have used the 
Sociocultural Theory to examine how the health care service quality may affect availability of skilled health workforce and vice versa. Second, a close examination of the existing literature shows that none of the existing studies have empirically examined the relationship between health care service quality and availability of skilled health workforce.

This paper is divided into seven sections. This section one provides the introduction. Section two provides theoretical perspective related to health care service quality and availability of skilled health workforce. Section three reviews the existing literature. Section four provides research methodology. Section five presents the results. Section six discusses the results and identifies the policy implications. Section seven provides conclusions and limitations.

\section{Theoretical Perspectives Related to Health Care Service Quality and Availability of Skilled Health Workforce}

This paper uses the Sociocultural Theory to examine the relationship between availability of skilled health workforce and quality of health care service delivery. The Sociocultural Theory, is one of the major theories in sociology and psychology, and is used to explain how an individual's attitudes, behaviour and mental functioning is affected by culture, institutions and historical context in which an individual is socialised. The Sociocultural Theory has been applied to many fields of study, including, entrepreneurship (Campanella et al. 2013; Garrett Jr and Holland 2015), tourism (Boley et al. 2014; Stylidis and Terzidou 2014), culture (Howard 2015; Carbaugh and Boromisza-Habashi 2015), strategic management (Villar 2014) and ethics (MacCormack 2016). There are hardly any studies available in the existing literature that has used the Sociocultural Theory to examine the relationship between health care service quality and availability of skilled workforce.

There are few studies that have tried to link the Sociocultural Theory to health care service quality. Waring (2005) study based on UK found that there is a 'culture of blame game' widely present in the medical profession. In an individualistic culture, individuals tend to put the blame for errors on third parties rather than take the blame for errors on themselves. According to Waring and Bishop (2010), lean management in the UK NHS hospital is strongly influenced by the social influence and employee resistance to changes at the workplace. Balarajan et al. (2011) found that the health care access has vastly improved in India; however, issues related to socioeconomic status, geography and gender is still affecting the health care service quality. Wagner and Bear (2009) argued that social influence, previous health care experience of nurses and organisational factors affect nurse's performance and healthcare service delivery. Papastavrou et al. (2014), Tobiano et al. (2015) and Hudgins (2016) argued that nurses are unable to carry out their tasks effectively because they are affected by limited resources. These resources include time, staffing and the ability of human resources department to recruit staff at the right place and at the right time.

There are other similar studies that have tried to link the Sociocultural Theory to the availability of skilled workforce. Sidani et al. (2004) found that the situational characteristics affect the patient outcomes. One key factor that is part of these situational characteristics is the availability of skilled workforce. Rowe et al. (2005) found that in the low and middle income countries, the health workers portray certain behaviours that are affected by the sociocultural environment in which they accomplish their tasks. Aboshaiqah (2016) argued that cultural traditions and beliefs in Saudi Arabia affect the skill level of medical staff. Miyake et al. (2016) argued that improving the availability of skilled workers during new births is a challenging task in conflicted areas.

The next subsection will review the existing literature.

\section{Literature Review}

Existing studies on health care service quality and availability of skilled workforce can be divided into two categories. The first group of scholars has found that health care service quality, that can be proxied by patient reported health outcomes, may influence the availability of skilled health workforce. Stewart (1995) found that the satisfaction of patients from health care service delivery is influenced by the skills and talents of doctors and a number of other factors. The quality of interaction between health service providers and patients determines the recovery rate of the patient. If the communication between health service providers and the patient is stressful, this may be reflected by slow recovery or deteriorating health condition of the patient. Brady and Cronin (2001) argued that if nurses and doctors are able to improve the reliability and responsiveness of the health care service, the health care service quality perceptions will improve. Vujicic et al. (2004) found that by improving working conditions of medical specialists, the problem of medical specialist migration can be effectively tackled in the USA. Tandon (2004) argued that the growing population size of India affects the number of skilled health workers that has to be hired by health centers. Reeves et al. (2005) study based on London's health care found that apart from education and training, factors such as, cleanliness and pay affect nurse reported outcomes. According to 
Aiken (2007), nurses continue to migrate from the health care industry in the USA. Non-wage policies can be used by the USA government to reduce migration of nurses. Feldman-Stewart and Brundage (2009) extended the patient-provider conceptual framework because communication is one of the key determinants of improving the health care service. Hannon et al. (2013) study on cancer patients in Canada found that care giver's involvement and patient autonomy needs to be balanced in order to improve satisfaction of oncology patients. Puet et al. (2013) study on Southern Bangladesh found that lack of financial resources has an adverse effect on the quality of health care service. In such situations, even if quality of healthcare workforce is present, they will not be able to improve the quality of the health care service delivery. McHugh et al. (2015) study based on the survey of 564 nurses in California found that there is a strong relationship between patient and nurse outcomes at the Kaiser Hospital as compared to the non-Magnet hospitals. Kaiser hospital has more qualified medical specialists and this is one of the reasons why patient outcomes are higher in the Kaiser hospital as compared to the non-Magnet hospitals.

The second group of scholars has found that availability of skilled health workforce may influence health care service quality. According to Bartlett (1984), Weinman (2004), Cooper et al. (2006) and Smedley et al. (2003) found that in the American society, African Americans and Latinos are more likely to encounter unpleasant interaction between health service providers and patients. Blegen et al. (2001) argued that more educated and experienced nurses made less medication errors as compared to their counterparts. Burgess (2004) and van Ryn and $\mathrm{Fu}(2004)$ found that ethnic discrimination in the provision of health care in the USA negatively influences health outcomes. Skevington et al. (2005) highlighted that quality of life is an important proxy for health care service. Health care in developed and developing countries has been provided by both private and public sectors. This indicates that the supply of skilled medical specialists is essential for improving quality of work life. Fung and Hays (2008) argued that patient reported outcomes are the best source of information that can be used to improve clinical practice. Maestad et al. (2010) study on health facilities in Tanzania found that medical specialists in rural Tanzania are not overloaded with patients. Medical specialists working at the clinics have sufficient idle time; hence, health workforce tends to be under loaded. Bullock and Firmstone (2011) study on UK's dental care found that education and training of dentist influence patient and dentist reported outcomes. Spilsbury et al. (2011) found that health centres that focus on increasing the number of nurses and doctors are not able to focus on factors that affect health care service quality. Some of these factors that health centres need to consider are training and development of staff and care organisation. Ten Hoope-Bender et al. (2014) found that if health centres improve the regulation and human resource management policies they would be able to hire more skilled, qualified and talented workforce.

\section{Research Methods}

The main aim of this study is to examine whether the availability of skilled health workforce (doctors and nurses) influence patient satisfaction from health service delivery. This is a quantitative study based on time series secondary data from the Organisation for Economic Cooperation and Development (OECD) database. The study utilises the 'Panel Data Modelling Technique' (PDMT) to examine the relationship between health care service quality and availability of skilled health workforce by drawing data from the OECD database. There are two reasons for selecting the USA, UK and Israel for this study. First, the research findings from the USA, UK and Israel can be compared because these are large developed countries in the global economic environment. Second, data from these three countries are readily available from the OECD database.

Data Collection: This study uses data from the OECD database. The OECD database is credible and reliable source for time series data. Three OECD countries were selected to be studied in this paper and these three countries are (1) USA, (2) UK and (3) Israel. Data on the dependent and independent variables used in this paper were obtained from year 2010 to 2015. Secondary data were missing for few years. In order to undertake time series analysis, the gaps in the missing values were filled by calculating simple and moving averages. For a few years, the authors of this paper provided judgemental estimation of the missing data by examining the past trends in the times series data. The data used in this paper was collected by the OECD under the Health Care Quality Indicators Project. This was a sustainable effort over a long period of time by the OECD member countries to collect data on health issues affecting the OECD member countries (OECD 2015). The Health Care Quality Indicators Project was initiated in the year 2003 and initially, there were 16 member countries that started collaborating to collect high quality data on health care indicators. To collect data on health care quality indicators, OECD countries designed a questionnaire (information sheets) that was given to relevant personnel from the Ministry of Health from each country. The Ministry of Health in each of these countries keep detailed information about health quality indicators for all the hospitals and health centres, irrespective of whether it is private or public hospital (OECD 2015). Since this was a collective effort by the OECD member countries, the 
Ministry of Health in each of the countries provided detailed information on the hospitals and health centres from year 2010 to 2015. The sample includes all the government and private hospitals in the UK, USA and Israel. The information was collected by using the information sheets designed by the ministries in each of the respective countries (OECD 2015).

\subsection{Independent Variables}

There were four independent variables used in this study. These four independent variables are discussed below:

Collaboration and consultation with patients on decisions related to health care service delivery: Since the patients are users of health service, their role in decision making related to health care service delivery will enhance patient's recovery. This measure in the OECD database was presented as the standardised rate per 100 patients. Collaboration and consultation with patients on decisions related to health care service delivery is essential for improving the quality of health care service delivery (Tritter and McCallum 2006; Boote et al. 2010; Paudyal et al. 2011).

Patient reported outcomes on getting clear instructions from the doctors: Clear instructions from the doctors on the use of medication, diet control, exercise and sleeping schedule are essential for faster recovery of patient's. If the instructions from the doctors are not clear, patients may end up taking the wrong medication and adopting poor lifestyle habits. As a result of this, the recovery of patients will be adversely affected (Payne et al. 2007; Davis et al. 2009; Legido-Quigley et al. 2015). This measure in the OECD database was presented as the standardised rate per 100 patients.

Patient reported outcomes on spending enough time with the doctor: There are many studies that found that patients are able to recover faster if they regularly visit and spend more time with the doctors (Longo 2007; Chung et al. 2009). The economic intuition behind this argument is that patients who care more about their health see doctors more regularly and spend more time with the doctors. This measure in the OECD database was presented as the standardised rate per 100 patients.

Patient reported outcomes on 'waiting time' for more than 4 weeks before getting a medical specialists appointment: There are many studies that indicate that the longer patients have to wait to get an appointment with the specialist, the more poor will be patient's health and the longer time it will take the patient to recover (Stoop et al. 2005; Leung et al. 2006). This measure in the OECD database was presented as the standardised rate per 100 patients.

\subsection{Dependent Variables}

There were six dependent variables used in this paper. These six dependent variables are discussed below:

Domestically trained doctors: Doctors that are locally trained doctors in each of the respective countries.

Foreign trained doctors: Foreign trained doctors were measured by the number of overseas trained doctors delivering health service in the USA, UK and Israel.

Doctor's total count: The doctor's total count is the total number of doctor's in the respective countries.

Domestically trained nurses: Domestically trained nurses are those trained locally in each of the respective countries.

Foreign trained nurses: Foreign trained nurses were measured by the number of overseas trained nurses working in the USA, UK and Israel.

Nurse's total: The nurse's total in the OECD countries was measured by counting the number of nurse's in each of the respective countries.

\subsection{Data Analysis}

The data for this study was analysed by using the Eview8 software. The Eviews8 software is very effective in handling panel time series data. This study only examined one way relationship between health care service quality and availability of skilled health workforce. Two way relationships between health care service quality and availability of skilled health workforce cannot be estimated as the problem of multicollinearity sets in if health care service quality proxies are used as dependent variable and availability of skilled health workforce proxies are used as independent variables.

\section{Results}

The descriptive statistics of the dependent variables measuring the availability of skilled health workforce are given in table 1 . On average, there were 101,018 domestically trained doctors and 43,180 foreign trained doctors 
in the USA, UK and Israel during the period 2010 to 2015. During the period 2010 to 2015, on average, there were 587,008 domestically trained nurses and 45,332 foreign trained nurses in the USA, UK and Israel. Some of these are doctors and nurses who have migrated to each of these respective countries.

Table 1. Summary Statistics for the Dependent Variables Measuring the Availability of Skilled Workforce (Note 1)

\begin{tabular}{|c|c|c|c|c|}
\hline Measure & $\sum D o m$ & $\sum D o m$ & $\sum$ Fore & $\sum$ Fore_Trainur \\
\hline Mean & 101018 & 587008 & 43180 & 45332 \\
\hline Median & 10413.00 & 40238.80 & 14853.00 & 5066.500 \\
\hline Maximum & 626866.0 & 3858563 & 207691.0 & 246291.0 \\
\hline Minimum & 10046.00 & 39356.00 & 14759.00 & 4528.000 \\
\hline Std. Dev. & 215860.1 & 1336190 & 67525.04 & 86088.42 \\
\hline Skewness & 2.140000 & 2.178756 & 2.140743 & 1.864933 \\
\hline Kurtosis & 5.780210 & 5.894791 & 5.782433 & 4.903964 \\
\hline Jarque-Bera & a 8.682657 & 9.122575 & 8.691022 & 5.845658 \\
\hline Probability & 0.013019 & 0.010449 & 0.012965 & 0.053781 \\
\hline Sum & 808143.0 & 4696063. & 345437.0 & 362653.0 \\
\hline \multicolumn{5}{|c|}{ 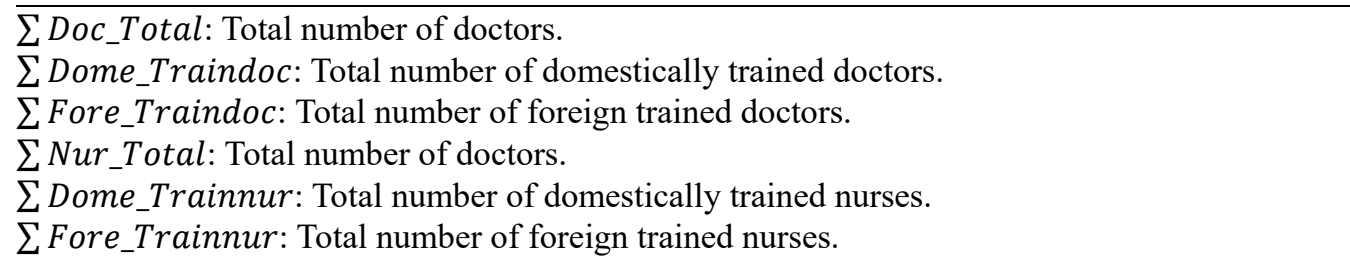 } \\
\hline
\end{tabular}

The descriptive statistics of the independent variables measuring the patient satisfaction from health care service delivery are given in table 2 . On average, 84 per 100 patients reported that they were consulted on decisions related to health care service delivery during the period 2010 to 2015 in the USA, UK and Israel. On average, 90 per 100 patients reported that they were given clear instructions from the medical specialists during the period 2010 to 2015 in the USA, UK and Israel. On average, 90 out of 100 patients reported that they had spent enough time with the doctor during the period 2010 to 2015 in the USA, UK and Israel. On average, 19 out of 100 patients reported that they have waited for more than 4 weeks before getting an appointment with the medical specialist during the period 2010 to 2015 in the three OECD countries studied in this paper (see table 2).

Table 2. Summary Statistics for the Independent Variables Measuring Patients Satisfaction from Health Care Service Delivery

\begin{tabular}{lllll}
\hline Measure & PAT_DECI & PAT_EASY_UNDER & PAT_ENOU_TIME & WAIT_FOURWK \\
\hline Mean & 84.0 & 90.0 & 90 & 19.0 \\
Median & 83.0 & 91.0 & 89.5 & 19.75000 \\
Maximum & 90.0 & 95.5 & 95.0 & 25.00000 \\
Minimum & 76.0 & 83.0 & 78.0 & 13.00000 \\
Std. Dev. & 4.60 & 4.4 & 5.4 & 4.396996 \\
Skewness & -0.04 & -0.6 & -1.1 & -0.100047 \\
Kurtosis & 2.20 & 2.1 & 3.5 & 1.587587 \\
Jarque-Bera & 0.21 & 0.76 & 1.7 & 0.678316 \\
Probability & 0.90 & 0.69 & 0.4 & 0.712370 \\
Sum & 668.0 & 722.50 & 715.6 & 150.2000 \\
\hline
\end{tabular}

PAT_DECI: Collaboration and consultation with patients on decisions related to health care service delivery.

PAT_EASY_UNDER: Patient reported outcomes on getting clear instructions from the doctors.

PAT_ENOU_TIME: Patient reported outcomes on spending enough time with the doctor

WAIT_FOURWK: Patient reported outcomes on waiting time more than 4 weeks before getting an appointment with the medical specialist. 
Table 3 shows the regression results for the relationship between patient satisfaction with health care service delivery and availability of skilled and qualified workforce in the three OECD countries. A one unit (Note 2) increase in patient reported outcomes on spending enough time with the medical specialist is associated with a 49933 unit decrease in the total number of doctors hired by hospitals in the USA, UK and Israel. If patient reported outcomes on spending enough time with medical specialist increases by 1 unit, the total number of nurses hired by hospitals in the USA, UK and Israel decreases by 290440 units. A one unit increase in patient reported outcomes on waited for more than four weeks before getting a medical specialist appointment are associated with a 105119 units increase in the total number of nurses hired by hospitals in the USA, UK and Israel. Patient reported outcomes on spending enough time with the medical specialist have a negative and significant effect on domestically trained doctors $(\beta=-37277 ; \mathrm{t}=-6.649746 ; \mathrm{p}<0.001)$ and indeed, a negative and significant impact on foreign trained doctors $(\beta=-11630.46 ; t=-6.664344 ; \mathrm{p}<0.001)$. Patient reported outcomes on waited for more than four weeks before getting a medical specialist appointment has a positive and statistically significant effect on domestically trained doctors $(\beta=-3241.07 ; \mathrm{t}=5.764110 ; \mathrm{p}<0.001)$, foreign trained doctors $(\beta=10050.71 ; \mathrm{t}=5.741234 ; \mathrm{p}<0.001)$, and domestically trained nurses $(\beta=96161.62 ; \mathrm{t}=5.400048 ; \mathrm{p}<0.05)$. Collaboration and consultation with patients in decisions related to health care service delivery is positive and significantly associated with the total number of domestically trained nurses hired by hospitals in the USA, UK and Israel $(\beta=82031.85 ; \mathrm{t}=4.199767 ; \mathrm{p}<0.05)$.

Table 3. Regression Results on the Relationship between Patient Satisfaction with Health Care Service Delivery and Availability of Skilled and Qualified Workforce in the Three OECD Countries

\begin{tabular}{|c|c|c|c|c|c|c|}
\hline Variable & $\sum D o c_{-} T o t a l$ & $\sum$ Dome_Traidoc & $c \sum$ Fore_Traidoc & $\sum N u r_{-} T o t a l$ & $\sum$ Dome_Trainur & $\sum$ Fore_Trainur \\
\hline PAT_DECI & $\begin{array}{l}4256.169 \\
(0.371925)\end{array}$ & $\begin{array}{l}2220.734 \\
(0.386599)\end{array}$ & $\begin{array}{l}752.9141 \\
(0.421023)\end{array}$ & $\begin{array}{l}81945.09 \\
(4.119338)^{*}\end{array}$ & $\begin{array}{l}82031.85 \\
(4.199767)^{*}\end{array}$ & $\begin{array}{l}-80.54972 \\
(-0.096617)\end{array}$ \\
\hline PAT_EASY_UN & N 21572.82 & 12516.56 & 3926.594 & 18041.89 & -274887.3 & 1186.459 \\
\hline DER & (1.482258) & $(1.713282)$ & $(1.726458)$ & (1.097666) & $(-18.33977)^{* * *}$ & $(1.722363)$ \\
\hline PAT_ENOU_TI & I - -49933.00 & -37277.00 & -11630.46 & -290440.2 & 16855.22 & -15555.06 \\
\hline $\mathrm{ME}$ & $(-4.471208)^{* * *}$ & $(-6.649746)^{* * *}$ & $(-6.664344)^{* * *}$ & $(-19.02645)^{* * *}$ & $(1.044385)$ & $(-24.31401)$ \\
\hline WAIT_FOURW & N 49610.50 & 32413.07 & 10050.71 & 105118.9 & 96161.62 & 8953.759 \\
\hline K & $(4.428522)$ & $(5.764110)^{* * *}$ & $(5.741234)^{* * *}$ & $(5.796133)^{* *}$ & $(5.400048)^{*}$ & (11.78005) \\
\hline $\mathrm{C}$ & $\begin{array}{l}1287034 \\
(0.932654)^{* * *}\end{array}$ & $\begin{array}{l}1485870 \\
(2.145055)^{*}\end{array}$ & $\begin{array}{l}469604.7 \\
(2.177642)^{*}\end{array}$ & $\begin{array}{l}16166795 \\
(9.996226)^{* * *}\end{array}$ & $\begin{array}{l}14998347 \\
(9.444820)^{* * *}\end{array}$ & $\begin{array}{l}1168199 \\
(67780.38)\end{array}$ \\
\hline R-squared & 0.848246 & 0.921498 & 0.921307 & 0.995198 & 0.994765 & 0.997702 \\
\hline Adjusted & 0.801552 & 0.897344 & 0.897094 & 0.988794 & 0.987785 & \\
\hline R-squared & & & & & & 0.994639 \\
\hline $\begin{array}{ll}\text { S.E. } & \text { o } \\
\text { regression } & \end{array}$ & of170705.1 & 85687.92 & 26676.16 & 150400.5 & 147676.4 & 6303.262 \\
\hline Sum square & $\mathrm{ed} 3.79 \mathrm{E}+11$ & $9.55 \mathrm{E}+10$ & $9.25 \mathrm{E}+09$ & $6.79 \mathrm{E}+10$ & $6.54 \mathrm{E}+10$ & \\
\hline resid & & & & & & $1.19 \mathrm{E}+08$ \\
\hline Log likelihood & -239.4706 & -227.0645 & -206.0596 & -102.7966 & -102.6504 & -77.41877 \\
\hline F-statistic & 18.16618 & 38.15042 & 38.04987 & 155.4200 & 142.5190 & 325.6851 \\
\hline $\operatorname{Prob}($ F-statistic) & 0.000031 & 0.000000 & 0.000000 & 0.000830 & 0.000944 & 0.000275 \\
\hline Mean dependen & $\mathrm{nt} 278190.7$ & 242054.4 & 87178.89 & 632346.3 & 587007.8 & \\
\hline var & & & & & & 45331.63 \\
\hline $\begin{array}{l}\text { S.D. dependen } \\
\text { var }\end{array}$ & nt383197.9 & 267440.7 & 83157.84 & 1420787. & 1336190. & 86088.42 \\
\hline Akaike & fo27.16340 & 25.78494 & 23.45106 & 26.94916 & 26.91261 & \\
\hline criterion & & & & & & 20.60469 \\
\hline Schwarz & 27.41072 & 26.03227 & 23.69839 & 26.99881 & 26.96226 & \\
\hline criterion & & & & & & 20.65434 \\
\hline Hannan-Quinn & 27.19750 & 25.81905 & 23.48516 & 26.61429 & 26.57773 & \\
\hline criteria. & & & & & & 20.26982 \\
\hline $\begin{array}{l}\text { Durbin-Watson } \\
\text { stat }\end{array}$ & 0.814285 & 1.156820 & 1.149617 & 2.476246 & 2.472460 & 4.075555 \\
\hline
\end{tabular}


Note: $* * *$ shows $\mathrm{p}<0.001 ; * *$ shows $\mathrm{p}<0.01 ; *$ shows $\mathrm{p}<0.05$. Coefficients are provided and t-statistics are given in brackets.

PAT_DECI: Collaboration and consultation with patients on decisions related to health care service delivery.

PAT_EASY_UNDER: Patient reported outcomes on getting clear instructions from the doctors.

PAT_ENOU_TIME: Patient reported outcomes on spending enough time with the doctor

WAIT_FOURWK: Patient reported outcomes on waiting time more than 4 weeks.

$\sum$ Doc_Total: Total number of doctors.

$\sum$ Dome_Traindoc: Total number of domestically trained doctors.

$\sum$ Fore_Traindoc: Total number of foreign trained doctors.

$\sum N u r_{-}$Total: Total number of doctors.

$\sum$ Dome_Trainnur: Total number of domestically trained nurses.

EFore_Trainnur: Total number of foreign trained nurses.

Table 4 shows the regression results on the relationship between patient satisfaction with health care service delivery and availability of skilled and qualified workforce in the USA. Patient reported outcomes on getting clear instructions from the medical specialist has a positive and significant impact on locally trained nurses $(\beta=62776.95 ; \mathrm{t}=9.911805 ; \mathrm{p}<0.05)$ in the USA.

Table 4. Regression Results on the Relationship between Patient Satisfaction with Health Care Service Delivery and Availability of Skilled and Qualified Workforce in the USA

\begin{tabular}{|c|c|c|c|c|c|c|}
\hline Variable & $\sum D o c \_T o t a l$ & $\sum$ Dome_Traidoc & $\sum$ Fore_Traidoc & $\sum N u r_{-} T o t a l$ & $\sum$ Dome_Trainur & $\sum$ Fore_Trainur \\
\hline \multirow[t]{2}{*}{ PAT_DECI } & -2369.967 & -1887.762 & -482.1254 & 6388.039 & 12659.64 & -1817.839 \\
\hline & $(-0.068854)$ & $(-0.076597)$ & $(-0.049322)$ & $(0.252933)$ & $(2.129983)$ & $(-0.550702)$ \\
\hline PAT_EASY_ & -32423.71 & -24732.24 & -7691.649 & 18149.60 & $62776.95^{*}$ & 16766.81 \\
\hline UNDER & $(-0.883988)$ & $(-0.941726)$ & $(-0.738415)$ & $(0.674377)$ & (9.911805) & (4.052397) \\
\hline PAT_ENOU & 49865.21 & 37793.11 & 12072.09 & 55105.48 & -2539.889 & -2304.106 \\
\hline _TIME & $(1.155802)$ & $(1.223421)$ & $(0.985294)$ & (1.740737) & $(-0.340933)$ & $(-0.655031)$ \\
\hline WAIT_FOU & -28119.73 & -21163.23 & -6956.505 & -26029.72 & -16196.93 & -11082.18 \\
\hline RWK & $(-1.097919)$ & $(-1.154034)$ & $(-0.956418)$ & $(-1.385100)$ & $(-3.662359)$ & $(-4.511908)$ \\
\hline \multirow[t]{2}{*}{$\mathrm{C}$} & 503725.7 & 394233.4 & 109501.2 & -1679674 & $-1959341^{*}$ & -471809.5 \\
\hline & $(0.505561)$ & $(0.552599)$ & $(0.386986)$ & $(-2.297506)$ & $(-11.38828)$ & $(-4.937664)$ \\
\hline R-squared & 0.804835 & 0.819024 & 0.761880 & 0.994120 & 0.999557 & 0.994336 \\
\hline Adjusted & 0.024175 & 0.095121 & -0.190598 & 0.970600 & 0.997786 & 0.971681 \\
\hline \multicolumn{7}{|l|}{ R-squared } \\
\hline $\begin{array}{l}\text { S.E. of } \\
\text { regression }\end{array}$ & 43659.68 & 31261.03 & 12398.90 & 32035.26 & 7538.964 & 4187.019 \\
\hline $\begin{array}{l}\text { Sum squared } \\
\text { resid }\end{array}$ & $1.91 \mathrm{E}+09$ & $9.77 \mathrm{E}+08$ & $1.54 \mathrm{E}+08$ & $1.03 \mathrm{E}+09$ & 56835979 & 17531132 \\
\hline $\log$ & -67.24344 & -65.23912 & -59.69053 & -65.38591 & -56.70539 & -53.17682 \\
\hline \multicolumn{7}{|l|}{ likelihood } \\
\hline F-statistic & 1.030968 & 1.131399 & 0.799893 & 42.26715 & 564.4581 & 43.89067 \\
\hline $\begin{array}{c}\text { Prob } \\
\text { (F-statistic) }\end{array}$ & 0.619553 & 0.599624 & 0.673864 & 0.114796 & 0.031556 & 0.112673 \\
\hline $\begin{array}{c}\text { Mean } \\
\text { dependent } \\
\text { var }\end{array}$ & 803694.0 & 604076.3 & 199617.5 & 4150809 . & 3876427. & 242715.2 \\
\hline
\end{tabular}




\begin{tabular}{|c|c|c|c|c|c|c|}
\hline $\begin{array}{c}\text { S.D. } \\
\text { dependent } \\
\text { var }\end{array}$ & 44197.19 & 32863.05 & 11363.20 & 186833.7 & 160239.2 & 24881.09 \\
\hline $\begin{array}{l}\text { Akaike info } \\
\text { criterion }\end{array}$ & 24.08115 & 23.41304 & 21.56351 & 23.46197 & 20.56846 & 19.39227 \\
\hline $\begin{array}{l}\text { Schwarz } \\
\text { criterion }\end{array}$ & 23.90761 & 23.23951 & 21.38998 & 23.28844 & 20.39493 & 19.21874 \\
\hline $\begin{array}{l}\text { Hannan-Qui } \\
\text { nn criteria. }\end{array}$ & 23.38648 & 22.71837 & 20.86884 & 22.76730 & 19.87379 & 18.69760 \\
\hline $\begin{array}{l}\text { Durbin-Wats } \\
\text { on stat }\end{array}$ & 2.004146 & 2.004146 & 2.004146 & 2.004146 & 2.004146 & 2.004146 \\
\hline \multicolumn{7}{|c|}{ Note: ${ }^{* *}$ shows $\mathrm{p}<0.001 ;{ }^{* *}$ shows $\mathrm{p}<0.01 ; *$ shows $\mathrm{p}<0.05$. Coefficients are provided and $\mathrm{t}$-statistics are given in brackets. } \\
\hline \multicolumn{7}{|c|}{ PAT_DECI: Collaboration and consultation with patients on decisions related to health care service delivery. } \\
\hline \multicolumn{7}{|c|}{ PAT_EASY_UNDER: Patient reported outcomes on getting clear instructions from the doctors. } \\
\hline \multicolumn{7}{|c|}{ PAT_ENOU_TIME: Patient reported outcomes on spending enough time with the doctor } \\
\hline \multicolumn{7}{|c|}{ WAIT_FOURWK: Patient reported outcomes on waiting time more than 4 weeks. } \\
\hline \multicolumn{7}{|c|}{$\sum$ Doc_Total: Total number of doctors. } \\
\hline \multicolumn{7}{|c|}{$\sum$ Dome_Traindoc: Total number of domestically trained doctors. } \\
\hline \multicolumn{7}{|c|}{$\sum$ Fore_Traindoc: Total number of foreign trained doctors. } \\
\hline \multicolumn{7}{|c|}{$\sum$ Nur_Total: Total number of doctors. } \\
\hline \multicolumn{7}{|c|}{$\sum$ Dome_Trainnur: Total number of domestically trained nurses. } \\
\hline$\sum$ Fore_Train & zur: Total nu & f foreign tra & & & & \\
\hline
\end{tabular}

Table 5 shows the regression results on the relationship between patient satisfaction with health care service delivery and the availability of skilled and qualified workforce in the UK. A one unit increase in patient reported outcomes on getting clear instructions from the medical specialist is associated with a 3872.375 units increase in the total number of nurses hired by hospitals in the UK. Patient reported outcomes in collaboration and consultation with patients in decisions related to health care service delivery has a significant and negative effect on the total number of domestically trained nurses $(\beta=-1859.648 ; \mathrm{t}=-22.38537 ; \mathrm{p}<0.05)$. Patient reported outcomes on getting clear instructions from the medical specialist $(\beta=6097.163 ; \mathrm{t}=35.20319 ; \mathrm{p}<0.01)$ and spending enough time with the medical specialist $(\beta=6966.066 ; \mathrm{t}=40.46273 ; \mathrm{p}<0.01)$ has a significant and positive impact on domestically trained nurses in the USA. Patient reported outcomes on waited for more than 4 weeks before getting a doctor's appointment has a significant and negative effect on domestically trained nurses $(\beta=-18659.83 ; \mathrm{t}=-29.46332 ; \mathrm{p}<0.05)$.

Table 5. Regression Results on the Relationship between Patient Satisfaction with Health Care Service Delivery and Availability of Skilled and Qualified Workforce in the UK

\begin{tabular}{|c|c|c|c|c|c|c|}
\hline Variable & $\sum D o c \_T o t a$ & $\sum$ Dome_Traidoc & $\sum$ Fore_Traidoc & $\sum N u r_{-}$Total $\rangle$ & $\sum$ Dome_Trainur & $\sum$ Fore_Trainur \\
\hline PAT_DECI & $\begin{array}{l}-72.30064 \\
(-7.133492)\end{array}$ & $\begin{array}{l}-161.5914 \\
(-0.200986)\end{array}$ & $\begin{array}{c}42.36279 \\
(0.187575)\end{array}$ & $\begin{array}{l}-1263.314 \\
(-7.409908)\end{array}$ & $\begin{array}{l}-1859.648^{*} \\
(-22.38537)\end{array}$ & $\begin{array}{c}-79.09644 \\
(-1.512670)\end{array}$ \\
\hline PAT_EASY_UNDER & $\begin{array}{l}80.91808 \\
(3.829361)\end{array}$ & $\begin{array}{l}1650.957 \\
(0.984930)\end{array}$ & $\begin{array}{c}524.1359 \\
(1.113156)\end{array}$ & $\begin{array}{c}3872.375 \\
(10.89431)^{*}\end{array}$ & $\begin{array}{l}6097.163 * * \\
(35.20319)\end{array}$ & $\begin{array}{c}-47.28953 \\
(-0.433783)\end{array}$ \\
\hline PAT_ENOU_TIME & $\begin{array}{l}-91.54013 \\
(-4.358186)\end{array}$ & $\begin{array}{l}1600.267 \\
(0.960451)\end{array}$ & $\begin{array}{c}221.4535 \\
(0.473160)\end{array}$ & $\begin{array}{c}2930.358 \\
(8.293852)\end{array}$ & $\begin{array}{l}6966.066 * * \\
(40.46273)\end{array}$ & $\begin{array}{c}271.3593 \\
(2.504184)\end{array}$ \\
\hline WAIT_FOURWK & $\begin{array}{l}-474.6095 \\
(-6.142386)\end{array}$ & $\begin{array}{l}-5358.483 \\
(-0.874241)\end{array}$ & $\begin{array}{c}-898.6300 \\
(-0.521931)\end{array}$ & $\begin{array}{l}-7077.551 \\
(-5.445342)\end{array}$ & $\begin{array}{l}-18659.83 * \\
(-29.46332)\end{array}$ & $\begin{array}{c}540.5073 \\
(1.355906)\end{array}$ \\
\hline
\end{tabular}




\begin{tabular}{|c|c|c|c|c|c|c|}
\hline $\mathrm{C}$ & $\begin{array}{l}21180.86 \\
(8.931353)\end{array}$ & $\begin{array}{l}-58359.26 \\
(-0.310222)\end{array}$ & $\begin{array}{c}-4889.369 \\
(-0.092525)\end{array}$ & $\begin{array}{c}311464.0 \\
(7.807698)\end{array}$ & $\begin{array}{c}-61626.38 \\
(-3.170398)\end{array}$ & $\begin{array}{c}62809.50 \\
(12234.86)\end{array}$ \\
\hline R-squared & 0.989180 & 0.760313 & 0.711610 & 0.998941 & 0.999878 & 0.982748 \\
\hline Adjusted R-squared & 0.945901 & -0.198436 & -0.441950 & 0.994706 & 0.999391 & 0.913739 \\
\hline S.E. of regression & 73.42996 & 5824.848 & 1636.220 & 1235.184 & 601.8660 & 378.8314 \\
\hline Sum squared resid & 5391.959 & 33928855 & 2677217. & 1525680. & 362242.7 & 143513.3 \\
\hline Log likelihood & -28.91634 & -55.15768 & -47.53922 & -45.85221 & -41.53856 & -38.76090 \\
\hline F-statistic & 22.85589 & 0.793026 & 0.616882 & 235.8661 & 2053.694 & 14.24086 \\
\hline Prob(F-statistic) & 0.155464 & 0.675695 & 0.728094 & 0.048792 & 0.016548 & 0.195889 \\
\hline Mean dependent var & 5697.000 & 111736.0 & 47089.17 & 667270.8 & 572817.0 & 85278.00 \\
\hline S.D. dependent var & 315.7037 & 5320.802 & 1362.595 & 16976.16 & 24397.15 & 1289.847 \\
\hline Akaike info criterion & 11.30545 & 20.05256 & 17.51307 & 16.95074 & 15.51285 & 14.58697 \\
\hline Schwarz criterion & 11.13191 & 19.87903 & 17.33954 & 16.77720 & 15.33932 & 14.41343 \\
\hline Hannan-Quinn criter. & 10.61078 & 19.35789 & 16.81840 & 16.25607 & 14.81818 & 13.89230 \\
\hline Durbin-Watson stat & 2.463638 & 2.463638 & 2.463638 & 2.463638 & 2.463638 & 2.463638 \\
\hline
\end{tabular}

Note: $* * *$ shows $\mathrm{p}<0.001$; $* *$ shows $\mathrm{p}<0.01 ; *$ shows $\mathrm{p}<0.05$. Coefficients are provided and t-statistics are given in brackets.

PAT_DECI: Collaboration and consultation with patients on decisions related to health care service delivery.

PAT_EASY_UNDER: Patient reported outcomes on getting clear instructions from the doctors.

PAT_ENOU_TIME: Patient reported outcomes on spending enough time with the doctor

WAIT_FOURWK: Patient reported outcomes on waiting time more than 4 weeks.

$\sum$ Doc_Total: Total number of doctors.

$\sum$ Dome_Traindoc: Total number of domestically trained doctors.

$\sum$ Fore_Traindoc: Total number of foreign trained doctors.

$\sum N u r_{-}$Total: Total number of doctors.

$\sum$ Dome_Trainnur: Total number of domestically trained nurses.

$\sum$ Fore_Trainnur: Total number of foreign trained nurses.

Table 6 shows the regression results on the relationship between patient satisfaction with health care service delivery and availability of skilled and qualified workforce in Israel. The research findings show that patient reported outcomes on getting clear instructions from the doctors has a positive and significant effect on domestically trained doctors $(\beta=33.72066 ; t=13.93989 ; p<0.05)$ in Israel.

Table 6. Regression Results on the Relationship between Patient Satisfaction with Health Care Service Delivery and Availability of Skilled and Qualified Workforce in Israel

\begin{tabular}{|c|c|c|c|c|c|c|}
\hline Variable & $\sum D o c \_T o t a l$ & ome_Traidoc & $\sum$ Fore_Traidoc & $\left.\sum N u r_{-} T o t a l\right\rangle$ & $\sum$ Dome_Trainur & $\sum$ Fore_Trainur \\
\hline PAT_DECI & $\begin{array}{c}21.75752 \\
(0.526726)\end{array}$ & $\begin{array}{c}36.39105 \\
(6.363983)\end{array}$ & $\begin{array}{c}-14.63353 \\
(-0.411184)\end{array}$ & $\begin{array}{c}4.407117 \\
(0.031537)\end{array}$ & $\begin{array}{c}63.92751 \\
(0.791481)\end{array}$ & $\begin{array}{l}-59.52040 \\
(-1.009282)\end{array}$ \\
\hline PAT_EASY_UNDER & $\begin{array}{c}25.70252 \\
(1.470890)\end{array}$ & $\begin{array}{l}33.72066^{*} \\
(13.93989)\end{array}$ & $\begin{array}{c}-8.018134 \\
(-0.532585)\end{array}$ & $\begin{array}{c}5.100461 \\
(0.086280)\end{array}$ & $\begin{array}{c}69.80794 \\
(2.043084)\end{array}$ & $\begin{array}{l}-64.70748 \\
(-2.593763)\end{array}$ \\
\hline PAT_ENOU_TIME & $\begin{array}{c}86.84221 \\
(0.516534)\end{array}$ & $\begin{array}{c}30.18986 \\
(1.297143)\end{array}$ & $\begin{array}{c}56.65235 \\
(0.391108)\end{array}$ & $\begin{array}{c}708.8825 \\
(1.246345)\end{array}$ & $\begin{array}{c}554.3862 \\
(1.686388)\end{array}$ & $\begin{array}{l}154.4963 \\
(0.643661)\end{array}$ \\
\hline WAIT_FOURWK & $\begin{array}{c}-25.72623 \\
(-0.279874)\end{array}$ & $\begin{array}{c}-0.149224 \\
(-0.011727)\end{array}$ & $\begin{array}{l}-25.57701 \\
(-0.322959)\end{array}$ & $\begin{array}{l}-332.8290 \\
(-1.070296)\end{array}$ & $\begin{array}{l}-225.1716 \\
(-1.252788)\end{array}$ & $\begin{array}{l}-107.6574 \\
(-0.820356)\end{array}$ \\
\hline $\mathrm{C}$ & $\begin{array}{c}13485.25 \\
(1.136509)\end{array}$ & $\begin{array}{c}1413.044 \\
(0.860257)\end{array}$ & $\begin{array}{c}12072.21 \\
(1.180896)\end{array}$ & $\begin{array}{l}-14785.72 \\
(-0.368343)\end{array}$ & $\begin{array}{c}-18480.27 \\
(-0.796524)\end{array}$ & $\begin{array}{l}3694.550 \\
(90.218095)\end{array}$ \\
\hline R-squared & 0.949913 & 0.999178 & 0.347923 & 0.882475 & 0.984302 & 0.959395 \\
\hline Adjusted R-squared & 0.749563 & 0.995892 & -2.260384 & 0.412374 & 0.921510 & 0.796973 \\
\hline S.E. of regression & 109.4952 & 15.15780 & 94.33740 & 370.4240 & 214.1007 & 156.3233 \\
\hline Sum squared resid & 11989.20 & 229.7588 & 8899.545 & 137213.9 & 45839.10 & 24436.97 \\
\hline Log likelihood & -31.31364 & -19.44944 & -30.41962 & -38.62624 & -35.33703 & -33.44991 \\
\hline F-statistic & 4.741284 & 304.0713 & 0.133390 & 1.877203 & 15.67551 & 5.906819 \\
\hline Prob(F-statistic) & 0.330098 & 0.042981 & 0.947989 & 0.494084 & 0.186955 & 0.298171 \\
\hline Mean dependent var & 25181.00 & 10351.00 & 14830.00 & 45048.60 & 40099.60 & 4949.000 \\
\hline
\end{tabular}




\begin{tabular}{|c|c|c|c|c|c|c|}
\hline S.D. dependent var & 218.7995 & 236.5088 & 52.24557 & 483.2240 & 764.2046 & 346.9340 \\
\hline Akaike info criterion & 12.10455 & 8.149814 & 11.80654 & 14.54208 & 13.44568 & 12.81664 \\
\hline Schwarz criterion & 11.93101 & 7.976281 & 11.63301 & 14.36855 & 13.27214 & 12.64310 \\
\hline Hannan-Quinn criter. & 11.40988 & 7.455145 & 11.11187 & 13.84741 & 12.75101 & 12.12197 \\
\hline Durbin-Watson stat & 2.363384 & 2.363384 & 2.363384 & 2.363384 & 2.363384 & 2.363384 \\
\hline \multicolumn{7}{|c|}{ Note: $* * *$ shows $\mathrm{p}<0.001 ; * *$ shows $\mathrm{p}<0.01 ; *$ shows $\mathrm{p}<0.05$. Coefficients are provided and $\mathrm{t}$-statistics are given in brackets. } \\
\hline \multicolumn{7}{|c|}{ PAT_DECI: Collaboration and consultation with patients on decisions related to health care service delivery. } \\
\hline \multicolumn{7}{|c|}{ PAT_EASY_UNDER: Patient reported outcomes on getting clear instructions from the doctors. } \\
\hline \multicolumn{7}{|c|}{ PAT_ENOU_TIME: Patient reported outcomes on spending enough time with the doctor } \\
\hline \multicolumn{7}{|c|}{ WAIT_FOURWK: Patient reported outcomes on waiting time more than 4 weeks. } \\
\hline \multicolumn{7}{|c|}{$\sum$ Doc_Total: Total number of doctors. } \\
\hline \multicolumn{7}{|c|}{$\sum$ Dome_Traindoc: Total number of domestically trained doctors. } \\
\hline \multicolumn{7}{|c|}{ ¿Fore_Traindoc: Total number of foreign trained doctors. } \\
\hline \multicolumn{7}{|c|}{$\sum$ Nur_Total: Total number of doctors. } \\
\hline \multicolumn{7}{|c|}{$\sum$ Dome_Trainnur: Total number of domestically trained nurses. } \\
\hline ¿Fore_Trainnur: T & mber of $\mathrm{f}$ & trained nu & & & & \\
\hline
\end{tabular}

\section{Discussions and Policy Implications}

The main aim of this paper was to examine the relationship between health care service quality (proxied by patient satisfaction with health care service delivery) and availability of skilled workforce in the USA, UK and Israel. The findings from this study show that if patients need to spend more time with the medical specialist, then hospitals will have to hire more doctors and nurses. This research finding holds collectively for the three OECD countries studied in this paper. There will be a chain effect generated if more medical specialists are hired by hospitals. Labour cost of the hospitals will increase; thereby, exerting more pressure on hospitals financial budget in the USA, UK and Israel. In addition to this, another important research finding from this paper is that if the waiting time of patient's increases, more doctors and nurses has to be hired in the USA, UK and Israel. Labour cost of the hospitals will increase; thereby, exerting more pressure on hospitals financial budget in the USA, UK and Israel and governments have to allocate more funds to the health ministries. The economic intuition behind this is that front office staff and nurses are in direct contact with the patients. They are the ones involved in planning and scheduling of patient appointments. The research findings from this study shows that more nurses need to be hired so that existing nurses are not constrained by work overload and they can undertake effective planning and scheduling practices in the USA, UK and Israel. If hospitals want to involve more patients on decisions related to health care service delivery, they need to hire more nurses. The findings from this study are similar to the findings of the studies conducted by Hannon et al. (2013) and McHugh et al. (2015). Hannon et al. (2013) argued that both caregivers and patient involvement in health care decision making is essential in order to improve patient reported outcomes on satisfaction from health care service delivery.

This study also argues that patient's feedback on the average time that he or she would like to spend with the medical specialist has to be aligned with the recruiting practices in both private and public hospitals in the USA, UK and Israel. If this practice can be adopted, patient reported outcomes on health care service delivery will improve. Interestingly, McHugh et al. (2015) found that in Germany patient outcomes are higher at the Kaiser Hospital as compared to the non-Magnet Hospitals. Kaiser hospital has more skilled staff and this is one of the reasons why patient outcome in the Kaiser hospital is higher. Parallel to this finding, this study found that patient reported outcomes, such as, need to spend more time with the medical specialist has a positive and significant effect on the number of doctors and nurses hired by hospitals in the USA, UK and Israel.

\section{Variations in the Research Findings}

The research findings in the context of the USA found that more nurses need to be hired if patients need clear instructions from the medical specialists. If more nurses are hired, they will be able to effectively plan and schedule doctor's appointment. As a result of this, doctors will be able to spend more time with the patients. A key factor here that may influence patient satisfaction with the health care service delivery is time. Effective planning and scheduling of doctors and patient appointment are essential for improving the quality time that the doctor will spend with the patient. This relationship is evident in the UK but not in Israel. Interestingly, in the context of Israel, there are different relationships that exist. The patient reported outcome on getting clear instructions from the doctors has a positive and significant effect on domestically trained doctors in Israel. In 
Israel, patients are more likely to understand the instructions given by the domestically trained doctors as compared to the foreign trained doctors. The Sociocultural Theory can be used to explain this point. Domestically trained doctors in Israel understand the local language and culture. Therefore, it is easier for them to communicate with the locals on the health issues that are affecting them. The findings from this study are also similar to the findings from the studies conducted by Rowe et al. (2005), Aboshaiqah (2016) and Miyake et al. (2016). These three studies found that socio-cultural factors affect the skill level and work ethics of the domestic health care staff.

There are few unique research findings that have emerged in the context of the UK. In the UK, an increase in the number of patient's consulting nurses related to their health issues will decrease the number of nurses required in hospitals. The reason behind this is that more discussion and consultation with patients in decisions related to health care service delivery will increase the workload of nurses. If the workload of nurses increases, holding all other factors constant, the turnover of nurses will increase. This implies that nurses will be dissatisfied from their work and would switch to other employments.

\section{Policy Implications}

This paper has four important policy implications. Policy makers can use both monetary and fiscal policies to enhance the health care service delivery in the USA, UK and Israel. First, fiscal policy instruments, particularly, government expenditure can be used to provide more scholarships to nurses and doctors. In case of the USA and UK, more nurse's needs to be hired while in Israel more domestically trained doctor's needs to be hired so that instructions from medical specialists are clear and easily understood by patients. Second, monetary policy measures can also be used by the government of the USA, UK and Israel to encourage investment in the health care sector. By reducing short term interest rates, the interbank interest rate on the overnight commercial bank loan market can be changed. As a result of this, the market short term interest rate can also be changed. Therefore, if the private sector invests more in the health care service sector, they would be able to increase the supply of domestically trained doctors and nurses in the market. Third, non-fiscal and non-monetary measures can be used to reduce the emigration of nurses from the USA and UK and domestically trained doctors from Israel. These non-fiscal and non-monetary measures may include improving working conditions, pay package, promotions and bonuses.

\section{Conclusion and Limitations}

This paper examined the relationship between health care service quality and availability of skilled health care workforce. The findings from this study showed that patient satisfaction with health care service delivery in the USA, UK and Israel is affected by the availability and number of doctors and nurses providing health care service. The number of hours spent by patients has to be aligned with the right number of doctors and nurses employed by hospitals. There are some variations in the research findings in these three countries. In the context of the USA and UK, if more doctors and nurses are hired - irrespective of domestically trained and foreign trained nurses - the patients are able to clearly understand the instructions given by doctors and nurses. However, there are few differences found in the context of Israel. In Israel, patients are clearly able to understand the instructions given by domestically trained doctors and nurses rather than the foreign trained doctors and nurses. One of the limitations from this study is that it examined and analysed data from only three countries. This limits the generalizability of the research findings to other OECD countries.

Future researchers can advance the existing literature on health care service quality and availability of skilled health workforce by conducting similar studies on other developed and developing countries.

\section{References}

Aboshaiqah, A. (2016). Strategies to address the nursing shortage in Saudi Arabia. International Nursing Review, 63(3), 499-506.

Aiken, L. H. (2007). US nurse labor market dynamics are key to global nurse sufficiency. Health Services Research, 42(3-2), 1299-1320.

Balarajan, Y., Selvaraj, S., \& Subramanian, S. V. (2011). Health care and equity in India. The Lancet, 377(9764), 505-515.

Bartlett, E. E., Grayson, M., Barker, R., Levine, D. M., Golden, A., \& Libber S. (1984). The effects of physician communications skills on patient satisfaction; recall, and adherence. Journal Chronic Dis, 37(9-10), 755764.

Blegen, M. A., Vaughn, T. E., \& Goode, C. J. (2001). Nurse experience and education: effect on quality of care. 
Journal of Nursing Administration, 31(1), 33-39.

Boley, B. B., McGehee, N. G., Perdue, R. R., \& Long, P. (2014). Empowerment and resident attitudes toward tourism: Strengthening the theoretical foundation through a Weberian lens. Annals of Tourism Research, 49, 33-50.

Boote, J., Baird, W., \& Beecroft, C. (2010). Public involvement at the design stage of primary health research: A narrative review of case examples. Health policy, 95(1), 10-23.

Brady, M. K., \& Cronin Jr, J. J. (2001). Some new thoughts on conceptualizing perceived service quality: A hierarchical approach. Journal of Marketing, 65(3), 34-49.

Bullock, A., \& Firmstone, V. (2011). A professional challenge: the development of skill-mix in UK primary care dentistry. Health Services Management Research, 24(4), 190-195.

Burgess, D. J., Fu, S. S., \& van Ryn, M. (2004). Why do providers contribute to disparities and what can be done about it?. Journal of General International Medicine, 19(11), 1154-1159.

Campanella, F., Della Peruta, M. R., \& Del Giudice, M. (2013). The role of sociocultural background on the characteristics and the financing of youth entrepreneurship. An exploratory study of university graduates in Italy. Journal of the Knowledge Economy, 4(3), 244-259.

Carbaugh, D., \& Boromisza-Habashi, D. (2015). Ethnography of Communication. John Wiley \& Sons, Inc.

Chung, V. C. H., Lau, C. H., Wong, E. M. C., Yeoh, E. K., \& Griffiths, S. M. (2009). Perceived quality of communication amongst outpatients in western and traditional Chinese medicine clinics in a Chinese population. Health Policy, 90(1), 66-72.

Cooper, L. A., Beach, M. C., Johnson, R. L., Inui, T. S. (2006). Delving below the surface. Understanding how race and ethnicity influence relationships in health care. Journal of General International Medicine, 21(1), S21-S27.

Davis, K., Doty, M. M., Shea, K., \& Stremikis, K. (2009). Health information technology and physician perceptions of quality of care and satisfaction. Health Policy, 90(2), 239-246.

Feldman-Stewart, D., \& Brundage, M. D. (2009). A conceptual framework for patient-provider communication: a tool in the PRO research tool box. Quality of Life Research, 18(1), 109-114.

Franco, L. M., Bennett, S., \& Kanfer, R. (2002). Health sector reform and public sector health worker motivation: a conceptual framework. Social Science \& Medicine, 54(8), 1255-1266.

Fung, C. H., \& Hays, R. D. (2008). Prospects and challenges in using patient-reported outcomes in clinical practice. Quality of Life Research, 17(10), 1297-1302.

Garrett Jr, R. P., \& Holland, D. V. (2015). Environmental effects on the cognitions of corporate and independent entrepreneurs. Small Business Economics, 45(2), 369-381.

Glinos, I. A. (2015). Health professional mobility in the European Union: Exploring the equity and efficiency of free movement. Health Policy, 119(12), 1529-1536.

Golan, O., Hansen, P., Kaplan, G., \& Tal, O. (2011). Health technology prioritization: which criteria for prioritizing new technologies and what are their relative weights?. Health Policy, 102(2), 126-135.

Hannon, B., Swami, N., Krzyzanowska, M. K., Leighl, N., Rodin, G., Le, L. W., \& Zimmermann, C. (2013). Satisfaction with oncology care among patients with advanced cancer and their caregivers. Quality of Life Research, 22(9), 2341-2349.

Howard, T. C. (2015). Why race and culture matter in schools: Closing the achievement gap in America's classrooms. Teachers College Press.

Hudgins, T. A. (2016). Resilience, job satisfaction and anticipated turnover in nurse leaders. Journal of nursing management, 24(1), E62-E69.

Legido-Quigley, H., Saliba, V., \& McKee, M. (2015). Exploring the experiences of EU qualified doctors working in the United Kingdom: A qualitative study. Health Policy, 119(4), 494-502.

Leung, G. M., Yeung, R. Y. T., Wong, I. O. L., Castan-Cameo, S., \& Johnston, J. M. (2006). Time costs of waiting, doctor-shopping and private-public sector imbalance: Microdata evidence from Hong Kong. Health Policy, 76(1), 1-12.

Lichtenberg, F. R. (2014). Pharmaceutical innovation and longevity growth in 30 developing and high-income 
countries, 2000-2009. Health Policy and Technology, 3(1), 36-58.

Longo, F. (2007). Implementing managerial innovations in primary care: can we rank change drivers in complex adaptive organizations?. Health Care Management Review, 32(3), 213-225.

MacCormack, P. (2016). Post-human ethics: embodiment and cultural theory. Routledge.

Maestad, O., Torsvik, G., \& Aakvik, A. (2010). Overworked? On the relationship between workload and health worker performance. Journal of Health Economics, 29(5), 686-698.

McHugh, M. D., Aiken, L. H., Eckenhoff, M. E., \& Burns, L. R. (2015). Achieving Kaiser Permanente quality. Health Care Management Review. https://doi.org/10.1097/hmr.0000000000000070

Miyake, S., Speakman, E. M., Currie, S., \& Howard, N. (2016). Community midwifery initiatives in fragile and conflict-affected countries: a scoping review of approaches from recruitment to retention. Health Policy and Planning, czw093.

OECD, (2015). Improving Value in Health: Measuring Quality. OECD Health Policy Studies,

Papastavrou, E., Andreou, P., \& Efstathiou, G. (2014). Rationing of nursing care and nurse-patient outcomes: A systematic review of quantitative studies. The International Journal of Health Planning \& Management, 29(1), 3-25.

Paudyal, V., Hansford, D., Cunningham, S., \& Stewart, D. (2011). Pharmacy assisted patient self care of minor ailments: a chronological review of UK health policy documents and key events 1997-2010. Health Policy, 101(3), 253-259.

Payne, K., Nicholls, S. G., McAllister, M., MacLeod, R., Ellis, I., Donnai, D., \& Davies, L. M. (2007). Outcome measures for clinical genetics services: a comparison of genetics healthcare professionals and patients' views. Health Policy, 84(1), 112-122.

Puett, C., Alderman, H., Sadler, K., \& Coates, J. (2015). 'Sometimes they fail to keep their faith in us': community health worker perceptions of structural barriers to quality of care and community utilisation of services in Bangladesh. Maternal \& Child Nutrition, 11(4), 1011-1022.

Reeves, R., West, E., \& Barron, D. (2005). The impact of barriers to providing high-quality care on nurses' intentions to leave London hospitals. Journal of Health Services Research \& Policy, 10(1), 5-9.

Rowe, A. K., de Savigny, D., Lanata, C. F., \& Victora, C. G. (2005). How can we achieve and maintain high-quality performance of health workers in low-resource settings?. The Lancet, 366(9490), 1026-1035.

Sidani, S., Doran, D. M., \& Mitchell, P. H. (2004). A Theory-Driven Approach to Evaluating Quality of Nursing Care. Journal of Nursing Scholarship, 36(1), 60-65.

Skevington, S. M., Day, R., Chisholm, A., \& Trueman, P. (2005). How much do doctors use quality of life information in primary care? Testing the trans-theoretical model of behaviour change. Quality of Life Research, 14(4), 911-922.

Smedley, B.D., Stith, A.Y., Nelson, A.R. (2003). Unequal Treatment: Confronting Racial and Ethnic Disparites in Health Care. Washington, DC: National Academies Press.

Spilsbury, K., Hewitt, C., Stirk, L., \& Bowman, C. (2011). The relationship between nurse staffing and quality of care in nursing homes: a systematic review. International Journal of Nursing Studies, 48(6), 732-750.

Stewart, M.A. (1995). Effective physician-patient communication and health outcomes: a review. CMAJ., 152(9), 1423-1433.

Stoop, A. P., Vrangbæk, K., \& Berg, M. (2005). Theory and practice of waiting time data as a performance indicator in health care: a case study from The Netherlands. Health Policy, 73(1), 41-51.

Stylidis, D., \& Terzidou, M. (2014). Tourism and the economic crisis in Kavala, Greece. Annals of Tourism Research, 44, 210-226.

Tandon, S. (2004). Challenges to the oral health workforce in India. Journal of Dental Education, 68(7 suppl), 28-33.

Ten Hoope-Bender, P., de Bernis, L., Campbell, J., Downe, S., Fauveau, V., Fogstad, H., \& Renfrew, M. J. (2014). Improvement of maternal and newborn health through midwifery. The Lancet, 384(9949), 1226-1235.

Tobiano, G., Marshall, A., Bucknall, T., \& Chaboyer, W. (2015). Patient participation in nursing care on medical 
wards: an integrative review. International Journal of Nursing Studies, 52(6), 1107-1120.

Tritter, J. Q., \& McCallum, A. (2006). The snakes and ladders of user involvement: moving beyond Arnstein. Health Policy, 76(2), 156-168.

van Ryn, M., Fu, S.S. (2003). Paved with good intentions: do public health and human service providers contribute to racial/ethnic disparities in health?. American Journal Public Health, 93(2), 248-255.

Villar, C., Alegre, J., \& Pla-Barber, J. (2014). Exploring the role of knowledge management practices on exports: A dynamic capabilities view. International Business Review, 23(1), 38-44.

Vujicic, M., Zurn, P., Diallo, K., Adams, O., \& Dal Poz, M. R. (2004). The role of wages in the migration of health care professionals from developing countries. Human Resources For Health, 2(1), 3.

Wagner, D., \& Bear, M. (2009). Patient satisfaction with nursing care: a concept analysis within a nursing framework. Journal of Advanced Nursing, 65(3), 692-701.

Waring, J. J. (2005). Beyond blame: cultural barriers to medical incident reporting. Social Science \& Medicine, 60(9), 1927-1935.

Waring, J. J., \& Bishop, S. (2010). Lean healthcare: rhetoric, ritual and resistance. Social Science \& Medicine, $71(7), 1332-1340$.

Weinman, J. (2004). Doctor-patient interaction: psychosocial aspects. In N.J. Smelser and P.B. Baltes (Ed.), International Encyclopedia of the Social and Behavioral Sciences. (3816-3821) Oxford, UK: Elsevier.

Young, R. (2013). How effective is an ethical international recruitment policy? Reflections on a decade of experience in England. Health Policy, 111(2), 184-192.

\section{Notes}

Note 1 . Table 1 provides the aggregate summary statistics for the three USA, UK, and Israel and does not represent summary statistics for each country.

Note 2. A unit increase is given as standardized rate per 100 patients. This condition applies to all "one unit' increase in independent variables reported in the research findings section.

\section{Copyrights}

Copyright for this article is retained by the author(s), with first publication rights granted to the journal.

This is an open-access article distributed under the terms and conditions of the Creative Commons Attribution license (http://creativecommons.org/licenses/by/4.0/). 